\section{Cat scratch esophagus}

Cat scratch lesion of the gastrointestinal tract is a rare entity. It was first reported in the colon, in 2007 [1]. A few case reports of cat scratch colon were published in the English literature following the initial description of this entity [2-4]. Recently, a case was described of linear esophageal tears in a man, similar to the colonic cat scratch lesion [5]. We report the second case of cat scratch esophagus and describe its natural clinical course.

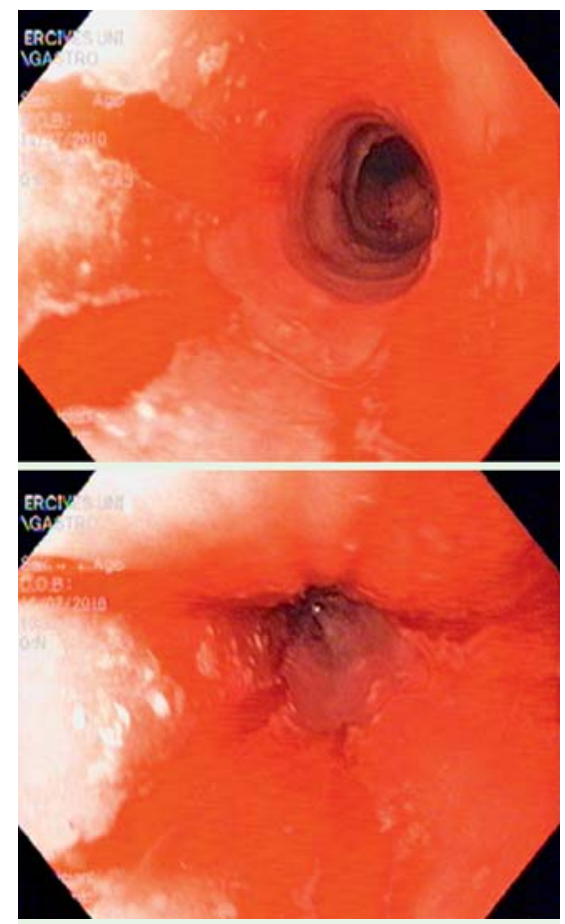

Fig. 1 First endoscopy showing cat scratch lesion on the esophageal wall.
A 45-year-old woman was admitted to our gastroenterology clinic with dyspepsia. She had undergone an upper endoscopy in another hospital 1 week before admission to our clinic. We performed an upper endoscopy in July 2010, and it revealed tears along the long axis of the esophagus. These superficial longitudinal lesions were evenly distributed around the circumference, resembling a cartwheel ( $\bullet$ Fig. 1). Mucosal biopsies from the esophageal mucosa showed detachment of the squamous epithelial layer with mild lymphoplasmacytic infiltration ( Fig.2). A control upper endoscopy of the patient in August 2010 demonstrated the complete healing of the esophageal lesions without any treatment.

Cat scratch colon is characterized by bright, superficial linear erythematous marks and parallel corkscrew lesions without significant hemorrhage. Colonic cat scratch lesions are usually localized in the right colon. The lesion has been observed mainly in normal patients with normal histology [1]. The single reported case of cat scratch lesion involving the esophagus was similar to the colonic counterparts [5].

The etiopathogenesis of this lesion is unclear. However, it has been suggested that the lesion is caused by barotrauma from air insufflation rather than by direct colonoscope trauma [4]. In our case, the patient's previous upper endoscopy probably gave rise to this morphology. We believe that the ileocecal valve in the right colon and the lower esophageal sphincter

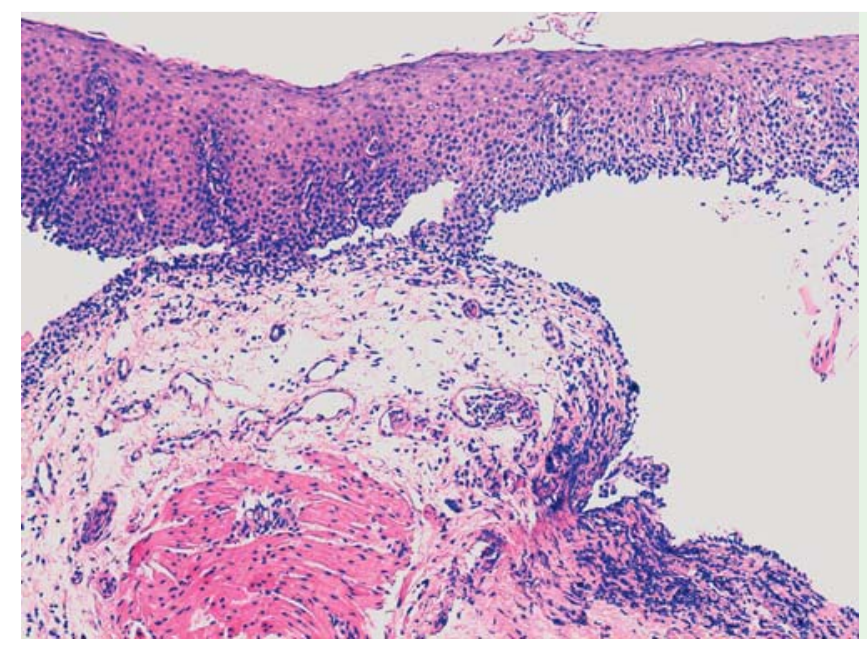

in the esophagus may act as barriers and increase the intraluminal pressure if they do not open properly at the right time during air insufflation.

Cat scratch morphology is accepted as an innocent finding due to its normal histology [2]. However, there were insufficient data regarding the natural clinical course of the lesion. Our case demonstrates that cat scratch esophagus is a self-healing lesion and confirms that it is an innocent lesion.

Endoscopy_UCTN_Code_CCL_1AB_2AC_3AH

\section{Competing interests: None}

\section{K. Deniz ${ }^{1}$, M. Başkol², Ş. Gürsoy², K. Güven ${ }^{2}$}

${ }^{1}$ Department of Pathology, Erciyes University, Medical School, Kayseri, Turkey

2 Department of Gastroenterology, Erciyes University, Medical School, Kayseri, Turkey

\section{References}

1 McDonell WM, Loura F, Pointon MJ et al. Cat scratch colon. Endoscopy 2007; 39: 459461

2 Katsinelos P, Kountouras J, Chatzimavroudis $G$ et al. "Cat scratch" colon: an impressive but innocent endoscopic finding. Endoscopy 2007; 39: 1026

3 Tominaga K, Shigiyama $F$, Ito $S$ et al. Emergence of "cat scratch colon" during a colonoscopy. Endoscopy 2008; 40: 353

4 Baudet JS, Diaz-Bethencourt D, Arguinarena $X$ et al. Cat scratch colon is caused by barotrauma secondary to insufflation during colonoscopy. Endoscopy 2008; 40: 878

5 Velayos B, Fernadez L, del-Olmo $L$ et al. Cat scratch esophagus: a new entity to be described. Rev Esp Enferm Dig 2011; 103: 427-428

\section{Bibliography}

Dol http://dx.doi.org/

10.1055/s-0031-1291522

Endoscopy 2012; 44: E44

(c) Georg Thieme Verlag KG

Stuttgart · New York

ISSN 0013-726X

\author{
Corresponding author \\ K. Deniz, MD \\ Erciyes University \\ Faculty of Medicine \\ Department of Pathology \\ 38039 Kayseri \\ Turkey \\ Fax: +90-352-4375273 \\ drkdeniz@yahoo.com
}

